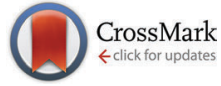

Cite this: Chem. Commun., 2015, 51, 11515

Received 27th April 2015, Accepted 8th June 2015

DOI: $10.1039 / \mathrm{c5cc03501e}$

www.rsc.org/chemcomm

\title{
Metal-free hydrogen evolution with nanoparticles derived from pyrene via two-photon ionization induced by laser irradiation $\uparrow$
}

\author{
Kei Ohkubo, ${ }^{\text {ab }}$ Naoki Kohno, ${ }^{a}$ Yusuke Yamada ${ }^{\text {ac }}$ and Shunichi Fukuzumi*abd
}

\begin{abstract}
Laser irradiation of a cyclohexane solution containing pyrene resulted in hydrogen evolution as pyrene was converted to a metal-free nanoparticle photocatalyst. When $\mathrm{C}_{6} \mathrm{H}_{12}$ was replaced by $\mathrm{C}_{6} \mathrm{D}_{12}, \mathrm{D}_{2}$ was mainly evolved. This result suggests that the hydrogen source is cyclohexane used as a solvent. Photocatalytic hydrogen evolution was also observed in an aqueous solution by using a water-soluble pyrene derivative.
\end{abstract}

Various approaches for light energy conversion into chemical energy have been developed in artificial photosynthesis. ${ }^{1-4}$ Heterogeneous metallic nanoparticles composed of semiconductor metallic oxides have been widely used for water splitting as catalysts in hydrogen production from water. ${ }^{5-8}$ However, the catalytic mechanism of hydrogen evolution is yet to be clarified. On the other hand, molecular metal-free photocatalysis under homogeneous conditions has recently gained special attention in organic synthesis, physical chemistry and green chemistry because of its low cost and mild reaction conditions for activation of substrates. ${ }^{9-13}$ Preparation of organic nanocrystals has been established by laser induced decomposition of organic crystals and particles. ${ }^{14-18}$ However, there have been few reports on photocatalytic reactions using heterogeneous organic nanoparticles as metal-free photocatalysts. ${ }^{19,20}$

Pyrene is known as an organic photosensitiser in the photochemical reactions. Two-photon excitation of pyrene produces photoionization products, the pyrene radical cation and a solvated electron under homogeneous conditions. The one-electron oxidation

\footnotetext{
${ }^{a}$ Department of Material and Life Science, Graduate School of Engineering, Osaka University, ALCA and SENTAN, Japan Science and Technology Agency (JST), Suita, Osaka 565-0871, Japan. E-mail: ookubo@chem.eng.osaka-u.ac.jp, fukuzumi@chem.eng.osaka-u.ac.jp

${ }^{b}$ Department of Bioinspired Science, Ewha Womans University, Seoul 120-750, Korea

${ }^{c}$ Department of Applied Chemistry \& Bioengineering, Graduate School of Engineering, Osaka City University, 3-3-138 Sugimoto, Sumiyoshi-ku, Osaka 558-8585, Japan

${ }^{d}$ Faculty of Science and Technology, Meijo University and ALCA and SENTAN, Japan Science and Technology Agency (JST), Tempaku, Nagoya, Aichi 468-8502, Japan

$\dagger$ Electronic supplementary information (ESI) available: Experimental and spectroscopic details. See DOI: 10.1039/c5cc03501e
}

and reduction potential of pyrene is +1.3 and $-2.0 \mathrm{~V} v s$. SCE in MeCN. ${ }^{21,22}$ The pyrene radical anion is generated by two-photon excitation and one-electron reduction by the solvated electron $\left[\mathrm{e}^{-}\right.$(solv)] or photoinduced electron transfer between the excited state of a pyrene molecule (S2 or S1 state) and the ground state of another pyrene molecule due to the higher-lying excited state $(E(\mathrm{~S} 1)=3.34 \mathrm{eV})^{23-26}$ than the HOMO-LUMO gap $(3.30 \mathrm{eV})$ in polar solvent. In nonpolar solvent, the solvated electron may have strong reducing ability to reduce a proton $\left(\mathrm{H}^{+}\right)$to hydrogen $\left(\mathrm{H}_{2}\right)$ without a metal catalyst.

$\mathrm{H}_{2}$ is primarily used in the chemical industry as a reactant and is proposed as an alternative energy source for the future. Catalytic $\mathrm{H}_{2}$ evolution systems have extensively been studied by using sacrificial electron donors, photosensitisers and electron mediators such as methyl viologen and an $\mathrm{H}_{2}$ evolution catalyst such as platinum. ${ }^{27-32}$ However, there has been no report on photocatalytic $\mathrm{H}_{2}$ evolution systems via proton reduction using an organic photosensitiser alone without any sacrificial electron source.

We report herein that metal-free photoinduced $\mathrm{H}_{2}$ evolution has been made possible by using pyrene as a precursor for nanoparticles. Efficient $\mathrm{H}_{2}$ evolution was observed in various organic solvents as well as water using pyrene alone as a metal-free organic photocatalyst under laser light irradiation at room temperature under atmospheric pressure. The reaction mechanism of laser-induced $\mathrm{H}_{2}$ evolution has been clarified based on the oxidized products, deuterium kinetic isotope effects and the dependence of the rate of $\mathrm{H}_{2}$ evolution on the laser intensity.

Nanosecond laser flash irradiation $(\lambda=355 \mathrm{~nm}, 10 \mathrm{~Hz}$, $40 \mathrm{~mJ}$ pulse $\mathrm{e}^{-1}$, i.d. $8 \mathrm{~mm}$ ) of a deaerated cyclohexane solution containing pyrene $(50 \mathrm{mM})$ for $90 \mathrm{~min}$ resulted in the formation of highly dispersed black nanoparticles in the solution. Fig. 1 shows the UV-vis absorption spectral change upon laser irradiation of pyrene in cyclohexane. The characteristic absorption bands at 306, 319 and $334 \mathrm{~nm}$ due to pyrene observed before irradiation disappeared and turned to the broad absorption from the UV-vis to near-IR region.

To characterize the nanoparticles, dynamic light scattering (DLS) measurements were performed for the photochemically 


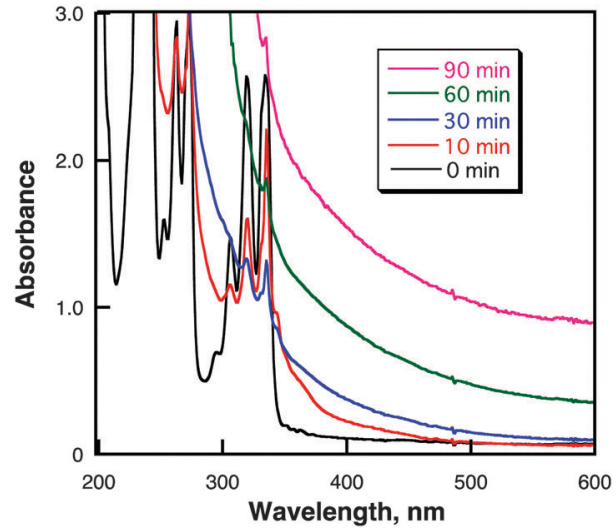

Fig. 1 UV-vis absorption spectral changes for growing pyrene nanoparticles observed in a cyclohexane solution $(2.5 \mathrm{~mL})$ containing pyrene $(50 \mu \mathrm{M})$ under laser irradiation $\left(\lambda=355 \mathrm{~nm} ; 40 \mathrm{~mJ} \mathrm{pulse}^{-1} ; 10\right.$ pulse $\left.\mathrm{s}^{-1}\right)$.
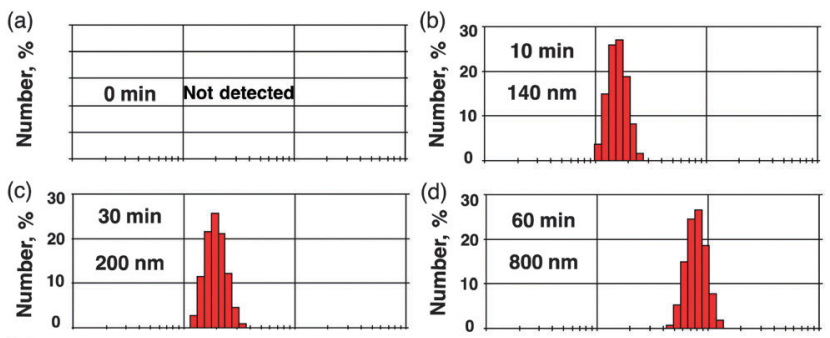

(e)

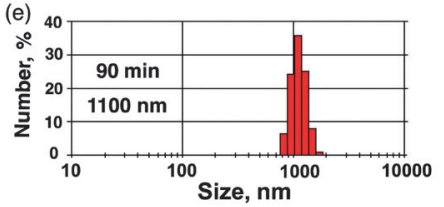

Fig. 2 Time course of DLS data of a cyclohexane solution $(2.5 \mathrm{~mL})$ containing pyrene $(50 \mu \mathrm{M})$ under laser irradiation $\left(\lambda=355 \mathrm{~nm} ; 40 \mathrm{~mJ}^{\text {pulse }}{ }^{-1} ; 10 \mathrm{~Hz}\right)$.

growing nanoparticles. The nanoparticles of $420 \mathrm{~nm}$ size were observed after laser irradiation for $30 \mathrm{~min}$ as shown in Fig. 2a.

The particle size grows by further laser irradiation to afford nanoparticles of $1100 \mathrm{~nm}$ size after the irradiation time of $90 \mathrm{~min}$. Transmission electron microscopy (TEM) measurements were performed to evaluate the transformation of pyrene nanoparticles after laser irradiation. TEM images after photoirradiation for $30 \mathrm{~min}$ (Fig. 3a and b) clearly exhibit small nanoparticles. After irradiation for $90 \mathrm{~min}$, the size of nanoparticles was enlarged (Fig. 3c and d). The IR spectra of nanoparticles showed that the characteristic peak at $3043 \mathrm{~cm}^{-1}$ due to the $\mathrm{C}-\mathrm{H}$ vibration disappeared and it was blueshifted to $2925 \mathrm{~cm}^{-1}$ with an increase in irradiation time (see Fig. $\mathrm{S} 1$ in the $\mathrm{ESI} \dagger$ ). This suggests that $\mathrm{C}-\mathrm{H}$ bonds of pyrene were broken in growing nanoparticles. To obtain the information of the $\mathrm{C}-\mathrm{H}$ bond of pyrene in the nanoparticle, $\mathrm{CHN}$ elemental analysis was performed in growing nanoparticles. The ratio of carbon and hydrogen was $94.4: 5.6$, which is virtually the same as the comparison of pyrene alone $(95.0: 5.0)$. Thus, the main component in the nanoparticle is the undamaged pyrene. The pyrene molecules on the particle surface may be dehydrogenated to form a pyrene polymer by the $\mathrm{C}-\mathrm{C}$ bond coupling reaction. The formation of pyrene oligomers was confirmed by the powder X-ray diffraction (a)

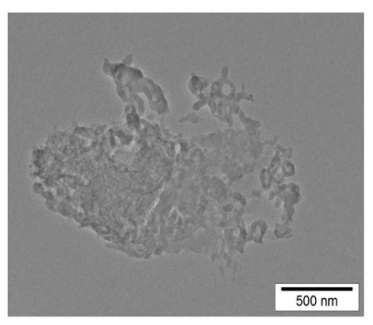

(b)

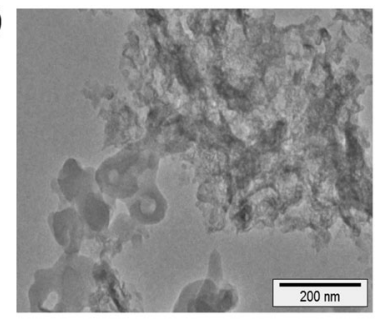

(c)

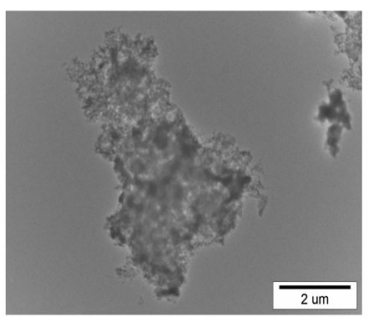

(d)

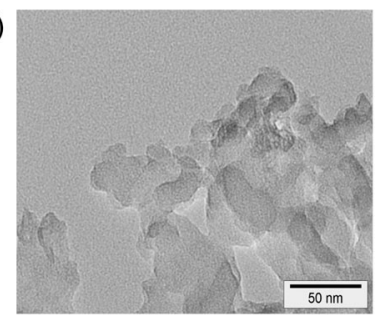

Fig. 3 TEM images of (a) a cyclohexane solution $(2.5 \mathrm{~mL})$ of pyrene $(50 \mu \mathrm{M})$ after laser light irradiation $\left(\lambda=355 \mathrm{~nm} ; 40 \mathrm{~mJ}\right.$ pulse $^{-1} ; 10$ pulse $\mathrm{s}^{-1}$ ) for $30 \mathrm{~min}$, (b) magnified figure of (a), (c) dispersion liquid of precipitation after laser light irradiation ( $\lambda=355 \mathrm{~nm} ; 40 \mathrm{~mJ}$ pulse ${ }^{-1} ; 10$ pulse s$^{-1}$ ) for $90 \mathrm{~min}$ and (d) magnified figure of (c).

(PXRD) measurements (Fig. S2 in the ESI $\dagger$ ). The XRD patterns with peaks at $2 \theta=11$ and $24^{\circ}$ due to the (001) and (220) planes were maintained after laser irradiation, indicating that the pyrene was not damaged in the nanoparticles.

Laser induced nanoparticle formation was initiated by the photo-ionization of pyrene to form a pyrene radical cation and a solvated electron [eqn (1)]. Hydrogen atom transfer from the cyclohexane radical anion $\left(\mathrm{Cy}^{\bullet-}\right)$, which is produced by the reduction of cyclohexane by solvated electron [eqn (2)], to the pyrene radical cation $\left(\mathrm{Py}^{\bullet+}\right)$ occurs to produce a hydrogenated pyrene neutral radical $\left(\mathrm{PyH}^{\bullet}\right)$ and a cyclohexyl radical $\left(\mathrm{C}_{6} \mathrm{H}_{11}{ }^{\bullet}\right)$ [eqn (3)]. Two molecules of $\mathrm{PyH}^{\bullet}$ react to give the pyrene dimer and $\mathrm{H}_{2}$ [eqn (4)]. The dimer was detected by MALDI-TOF-MS

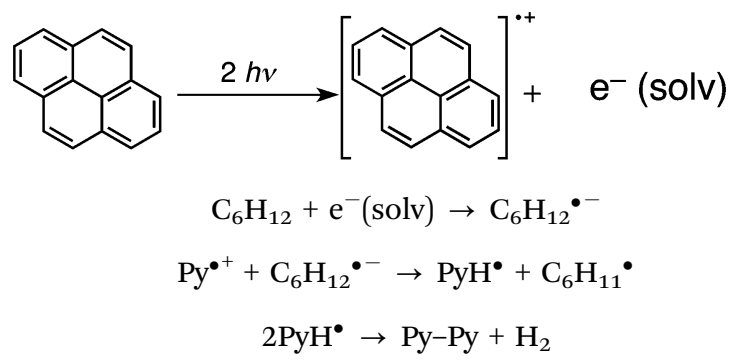

measurements (see Fig. S3 in the ESI $\dagger$ ). The resulting $\mathrm{C}_{6} \mathrm{H}_{11} \bullet$ is converted to cyclohexene by disproportionation, which was detected by GC-MS analysis (Fig. S4 in the ESI $\dagger$ ). Butadiene and propene were also detected as side products. The further oligomerization of pyrene occurred by laser irradiation to form the pyrene nano-aggregates.

On the basis of the above-mentioned reaction mechanism in eqn (4), the laser-induced dimerization of pyrene radicals results in $\mathrm{H}_{2}$ evolution. $\mathrm{H}_{2}$ evolution was successfully detected by GC experiments in the reaction of pyrene in cyclohexane under nanosecond laser irradiation at $355 \mathrm{~nm}$ as shown in Fig. 4. The TON of the 


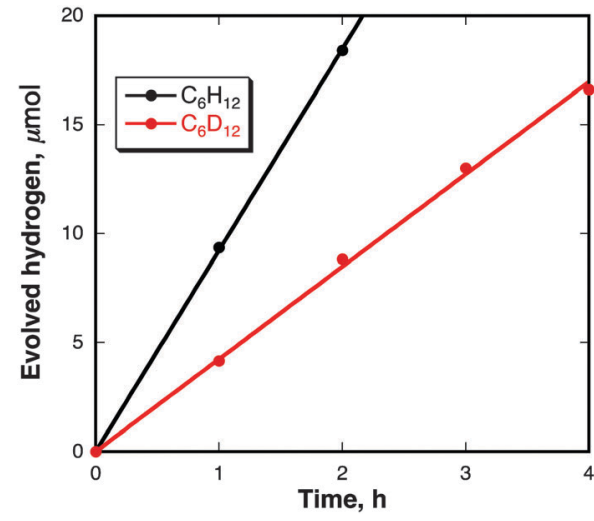

Fig. 4 Time courses of the amount of evolved $\mathrm{H}_{2}$ and $\mathrm{D}_{2}$ under laser irradiation ( $\lambda=355 \mathrm{~nm} ; 20 \mathrm{~mJ}$ pulse ${ }^{-1} ; 10$ pulse $^{-1}$ ) of a cyclohexane or cyclohexane- $d_{12}$ solution $(2.5 \mathrm{~mL})$ containing pyrene $(0.5 \mathrm{mM})$.

catalysts for $\mathrm{H}_{2}$ evolution was 2000 for $7 \mathrm{~h}$ based on the initial moles of pyrene in cyclohexane where the reaction conditions are $[\mathrm{Py}]=50 \mu \mathrm{M}, 40 \mathrm{~mJ}$ pulse $^{-1}$ at $\lambda=355 \mathrm{~nm}$ in cyclohexane $(2.5 \mathrm{~mL})$. No deactivation was observed in laser irradiation for $7 \mathrm{~h}$ (Fig. S5 in the ESI $\dagger$ ). When cyclohexane was replaced by cyclohexane- $d_{12}$ as a solvent, $\mathrm{D}_{2}$ gas was selectively evolved (data are shown in Fig. S6 in the ESI $\dagger$ ). ${ }^{33}$ The kinetic isotope effect (KIE) value for $\mathrm{H}_{2}$ evolution was determined to be 2.1. Thus, the rate-determining step of $\mathrm{H}_{2}$ evolution is carbon-hydrogen bond cleavage of the cyclohexane radical anion by hydrogen atom transfer to the pyrene radical cation. Indeed, no $\mathrm{H}_{2}$ evolution was observed in cyclohexene instead of cyclohexane (Fig. S7 in the ESI $\dagger$ ). $\mathrm{H}_{2}$ evolution also occurred when the laser light excitation wavelength was changed from $355 \mathrm{~nm}$ to $532 \mathrm{~nm}$ by an Nd:YAG laser as a light source (Fig. S8 in the ESI $\dagger$ ) because pyrene nanoparticles show a strong and broad absorption band covering the whole visible region as previously shown in Fig. 1.

The dependence of the rate of $\mathrm{H}_{2}$ evolution on the laser intensity was examined using different laser power intensities at $355 \mathrm{~nm}\left(0-20 \mathrm{~mJ}\right.$ pulse $\left.{ }^{-1}\right)$ as shown in Fig. 5a. The initial rates of $\mathrm{H}_{2}$ evolution are proportional to the second power of the laser intensity as shown in Fig. 5b. This suggests that an ionization reaction of two-photon absorbed species may be involved in the photocatalytic $\mathrm{H}_{2}$ evolution. The maximum quantum yield observed was $7.9 \%$ when the laser power is $40 \mathrm{~mJ}$ pulse $^{-1}$ at $355 \mathrm{~nm}$. The efficiency of the photocatalytic $\mathrm{H}_{2}$ evolution is affected by the solvent polarities as shown in Table 1 . The efficiency of photocatalytic $\mathrm{H}_{2}$ evolution is highest for cyclohexane and lowest for dimethylsulfoxide in the series of solvents. ${ }^{34}$ This suggests that electron reducing ability of solvated electron generated by photoionisation of pyrene in non-polar cyclohexane is much higher than in the polar solvent due to the stabilization of solvated electron.

On the basis of the above-mentioned results, the reaction mechanism of photocatalytic $\mathrm{H}_{2}$ evolution from pyrene nanoparticles (Py-NP) in cyclohexane (CyH) is shown in eqn (5)-(9). Two-photon ionization of Py-NP is much easier than the pyrene monomer, yielding a Py-NP radical cation $\left(\mathrm{Py}-\mathrm{NP}^{\bullet+}\right)$ and a cyclohexane radical anion $\left(\mathrm{C}_{6} \mathrm{H}_{12}{ }^{\bullet-}\right)$ [eqn (5)]. Hydrogen atom (a)

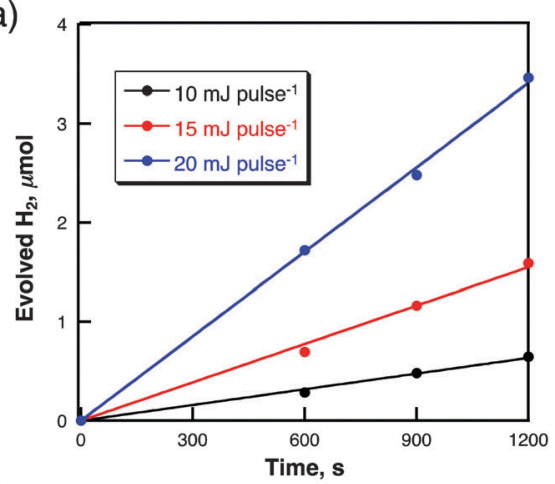

(b)

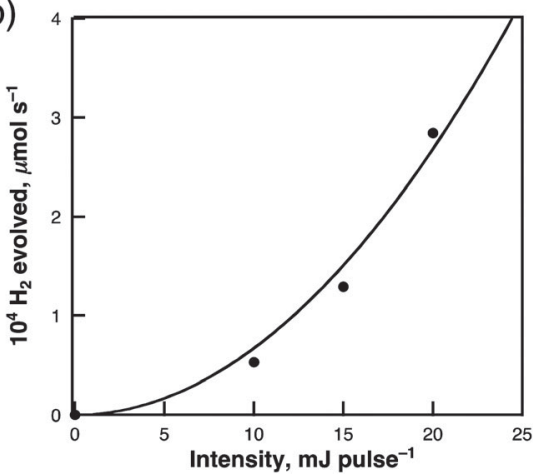

Fig. 5 (a) Time courses of the amount of evolved $\mathrm{H}_{2}$ in cyclohexane $(2.5 \mathrm{~mL})$ containing pyrene particles $(0.25 \mathrm{mg})$ under laser light irradiation $\left(\lambda=355 \mathrm{~nm} ; 10,15\right.$ or $20 \mathrm{~mJ}$ pulse ${ }^{-1} ; 10$ pulse $\left.^{-1}\right)$ and (b) Plot of the rate of $\mathrm{H}_{2}$ evolution vs. laser intensity. A fitted line was drawn by a secondorder function

Table 1 Rates of evolved $\mathrm{H}_{2}$ from Py-NP in various solvents ${ }^{a}$

\begin{tabular}{llc}
\hline Solvent & Dielectric constant & $\mathrm{H}_{2}\left(\mu \mathrm{mol} \mathrm{h}^{-1}\right)$ \\
\hline$n$-Heptane & 1.9 & 5.7 \\
Cyclohexane & 2.0 & 14 \\
2-Propanol & 18 & 2.6 \\
Acetone & 20 & 3.2 \\
Acetonitrile & 37 & 4.6 \\
Dimethylsulfoxide & 47 & 0.1
\end{tabular}

${ }^{a}$ Conditions: solvent: $2.5 \mathrm{~mL}$; pyrene: $0.50 \mathrm{mM}$; nanosecond laser $\left(\lambda=355 \mathrm{~nm} ; 20 \mathrm{~mJ}\right.$ pulse $\mathrm{s}^{-1} ; 10$ pulse $\left.\mathrm{s}^{-1}\right)$, under $\mathrm{N}_{2}$.

transfer from $\mathrm{C}_{6} \mathrm{H}_{12}{ }^{\bullet-}$ to Py-NP ${ }^{\bullet+}$ occurs [eqn (6)], followed by electron transfer from $\mathrm{C}_{6} \mathrm{H}_{11}{ }^{-}$to $\mathrm{Py}-\mathrm{NP}(-\mathrm{H})^{+}$[eqn (7)] and radical coupling with the release of $\mathrm{H}_{2}$ [eqn (8)]. Cyclohexyl radicals $\left(\mathrm{C}_{6} \mathrm{H}_{11}{ }^{\bullet}\right)$ split disproportionately to yield cyclohexene and cyclohexane [eqn (9)]. The total stoichiometry is given by eqn (10) by summing up eqn (5)-(9).

$$
\begin{aligned}
& \mathrm{Py}-\mathrm{NP}+\mathrm{C}_{6} \mathrm{H}_{12}+2 h \nu \rightarrow \mathrm{Py}^{-\mathrm{NP}^{\bullet+}}+\mathrm{C}_{6} \mathrm{H}_{12}{ }^{\bullet-} \\
& \text { Py-NP }{ }^{\bullet+}+\mathrm{C}_{6} \mathrm{H}_{12}{ }^{\bullet-} \rightarrow \text { Py-NP(}(-\mathrm{H})^{+}+\mathrm{C}_{6} \mathrm{H}_{11}{ }^{-} \\
& \text {Py-NP(-H })^{+}+\mathrm{C}_{6} \mathrm{H}_{11}{ }^{-} \rightarrow \text { Py-NP(-H) }{ }^{\bullet}+\mathrm{C}_{6} \mathrm{H}_{11}{ }^{\bullet} \\
& 2 \mathrm{Py}-\mathrm{NP}(-\mathrm{H})^{\bullet} \rightarrow(\mathrm{Py}-\mathrm{NP})_{2}+\mathrm{H}_{2} \\
& 2 \mathrm{C}_{6} \mathrm{H}_{11} \bullet \rightarrow \mathrm{C}_{6} \mathrm{H}_{10}+\mathrm{C}_{6} \mathrm{H}_{12}
\end{aligned}
$$


$n$ Py-NP $+(n-1) \mathrm{C}_{6} \mathrm{H}_{12} \rightarrow(\mathrm{Py}-\mathrm{NP})_{n}+(n-1) \mathrm{C}_{6} \mathrm{H}_{10}+(n-1) \mathrm{H}_{2}$

No nanoparticle of pyrene was formed in an aqueous solution by the laser photoirradiation at $355 \mathrm{~nm}$. Thus, no $\mathrm{H}_{2}$ evolution was observed under photoirradiation. When pyrene was replaced by sodium pyrene-1-acetate used as a water-soluble photosensitiser, the nanoparticle formation and $\mathrm{H}_{2}$ evolution occurred in an aqueous solution under otherwise the same reaction conditions (Fig. S9 in the ESI $\dagger$ ). We also examined $\mathrm{H}_{2}$ evolution using other hydrocarbons instead of pyrene. Nanoparticles were also formed under the same laser-irradiation conditions. Nanoparticles of coronene and 9,10diphenylanthracene were effective as $\mathrm{H}_{2}$-evolution photocatalysts. However, the rates of $\mathrm{H}_{2}$ evolution were 1.4, 1.1 and $0 \mu \mathrm{mol} \mathrm{h}{ }^{-1}$ for 9,10-diphenylanthracene, coronene and rubrene, respectively, which are significantly lower than the value of pyrene $\left(4.6 \mu \mathrm{mol} \mathrm{h}{ }^{-1}\right)$ in acetonitrile. In the case of rubrene as a red dye, no nanoparticle was formed without $\mathrm{H}_{2}$ evolution. It is difficult to form oligomers as precursors of $\mathrm{H}_{2}$-evolution catalysts because of the more delocalized $\pi$-radical cation than pyrene radical cation. In particular, the radical cations of rubrene and 9,10-diphenylanthracene are very stable in solution without any reaction such as dimerization.

In conclusion, pyrene nanoparticles have been demonstrated to act as efficient metal free organic photocatalysts for $\mathrm{H}_{2}$ evolution from various solvents. Cyclohexane used as a solvent is the most effective hydrogen source in $\mathrm{H}_{2}$ evolution with pyrene nanoparticles. The rate of $\mathrm{H}_{2}$ evolution increased with increasing laser intensity, exhibiting a second power dependence, because $\mathrm{H}_{2}$ was evolved via the two-photon ionization of pyrene followed by hydrogen atom transfer from the cyclohexane radical anion to the pyrene radical cation. Pyrene radical cations dimerise to form oligomer nanoparticles as more effective photocatalysts for $\mathrm{H}_{2}$ evolution. This is the first report of catalytic $\mathrm{H}_{2}$ evolution using an organic nanoparticle photocatalyst without inorganic material.

This work was supported by Grants-in-Aid (no. 26620154 and 26288037 to K.O. and no. 24350069 and 25600025 to Y.Y.) from the Ministry of Education, Culture, Sports, Science and Technology (MEXT); ALCA and SENTAN projects from JST, Japan (to S.F.). We acknowledge Research Centre for Ultra-Precision Science \& Technology in Osaka University for TEM measurements.

\section{Notes and references}

1 J. Barber, Chem. Soc. Rev., 2009, 38, 185-196.

2 N. S. Lewis and D. G. Nocera, Proc. Natl. Acad. Sci. U. S. A., 2006, 103, 15729-15735.

3 R. E. Blankenship, D. M. Tiede, J. Barber, G. W. Brudvig, G. Fleming, M. Ghirardi, M. R. Gunner, W. Junge, D. M. Kramer, A. Melis, T. A. Moore, C. C. Moser, D. G. Nocera, A. J. Nozik, D. R. Ort, W. W. Parson, R. C. Prince and R. T. Sayre, Science, 2011, 332, 805-809.

4 M. G. Walter, E. L. Warren, J. R. McKone, S. W. Boettcher, Q. X. Mi, E. A. Santori and N. S. Lewis, Chem. Rev., 2010, 110, 6446-6473.

5 M. Hambourger, A. Brune, D. Gust, A. L. Moore and T. A. Moore, Photochem. Photobiol., 2005, 81, 1015-1020.
6 R. Abe, K. Hara, K. Sayama, K. Domen and H. Arakawa, J. Photochem. Photobiol., A, 2000, 137, 63-69.

7 E. Reisner, D. J. Powell, C. Cavazza, J. C. Fontecilla-Camps and F. A. Armstrong, J. Am. Chem. Soc., 2009, 131, 18457-18466.

8 A. Le Goff, V. Artero, B. Jousselme, P. D. Tran, N. Guillet, R. Métayé, A. Fihri, S. Palacin and M. Fontecave, Science, 2009, 326, 1384-1387.

9 (a) P. D. Morse and D. A. Nicewicz, Chem. Sci., 2015, 6, 270-274; (b) N. J. Gesmundo and D. A. Nicewicz, Beilstein J. Org. Chem., 2014, 10, 1272-1281.

10 C. K. Prier, D. A. Rankic and D. W. C. MacMillan, Chem. Rev., 2013, 113, 5322-5363.

11 A. Aguirre-Soto, C.-H. Lim, A. T. Hwang, C. B. Musgrave and J. W. Stansbury, J. Am. Chem. Soc., 2014, 136, 7418-7427.

12 (a) S. Fukuzumi, K. Ohkubo and T. Suenobu, Acc. Chem. Res., 2014, 47, 1455-1464; (b) S. Fukuzumi and K. Ohkubo, Chem. Sci., 2013, 4, 561-574; (c) S. Fukuzumi and K. Ohkubo, Org. Biomol. Chem., 2014, 12, 6059-6071.

13 E. Bernoud, C. Lepori, M. Mellah, E. Schulz and J. Hannedouche, Catal. Sci. Technol., 2015, 5, 2017-2037.

14 (a) T. Asahi, T. Sugiyama and H. Masuhara, Acc. Chem. Res., 2008, 41, 1790-1798; (b) T. Sugiyama, S.-i. Ryo, I. Oh, T. Asahi and H. Masuhara, J. Photochem. Photobiol., A, 2009, 207, 7-12.

15 H. Tabata, M. Akamatsu, M. Fujii and S. Hayashi, Jpn. J. Appl. Phys., 2007, 46, 4338-4343.

16 A. Ibanez, S. Maximov, A. Guiu, C. Chaillout and P. L. Baldeck, Adv. Mater., 1998, 10, 1540-1543.

17 J. Ye, H.-Z. Chen and M. Wang, J. Mater. Sci., 2003, 38, 4021-4025.

18 A. H. Matsui, K. Mizuno, O. Nishi, Y. Matsushima, M. Shimizu, T. Goto and M. Takeshima, Chem. Phys., 1995, 194, 167-174.

19 (a) X. Wang, K. Maeda, A. Thomas, K. Takanabe, G. Xin, J. M. Carlsson, K. Domen and M. Antonietti, Nat. Mater., 2009, 8, 76-80; (b) Y. Cui, Z. Ding, X. Fu and X. Wang, Angew. Chem., Int. Ed., 2012, 51, 11814-11818; (c) Z. Lin and X. Wang, Angew. Chem., Int. Ed., 2013, 52, 1735-1738; (d) Y. Zheng, L. Lin, X. Ye, F. Guo and X. Wang, Angew. Chem., Int. Ed., 2014, 53, 11926-11930; (e) G. Zhang, M. Zhang, X. Ye, X. Qin, S. Lin and X. Wang, Adv. Mater., 2014, 26, 805-809.

20 K. Ohkubo, N. Kohno, Y. Yamada and S. Fukuzumi, Chem. Sci., 2015, 6, 666-674.

21 S. Fukuzumi, K. Ohkubo, H. Imahori and D. M. Guldi, Chem. - Eur. J., 2003, 9, 1585-1593.

22 S. Fukuzumi, J. Yuasa, N. Satoh and T. Suenobu, J. Am. Chem. Soc., 2004, 126, 7585-7594.

23 J. T. Richards, G. West and K. T. John, J. Phys. Chem., 1970, 74, 4137.

24 A. R. Watkins, J. Phys. Chem., 1976, 80, 713-717.

25 X. Chen, S. Shen, L. Guo and S. S. Mao, Chem. Rev., 2010, 110, 6503.

26 M. G. Walter, E. L. Warren, J. R. McKone, S. W. Boettcher, Q. Mi, E. A. Santori and N. S. Lewis, Chem. Rev., 2010, 110, 6446-6470.

27 W. J. Youngblood, S.-H. A. Lee, K. Maeda and T. E. Mallouk, Acc. Chem. Res., 2009, 42, 1966-1972.

28 A. Kudo and Y. Miseki, Chem. Soc. Rev., 2009, 38, 253-278.

29 R. M. Navarro, M. C. A. Galván, J. A. V. de la Mano, S. M. Al-Zahrani and J. L. G. Fierro, Energy Environ. Sci., 2010, 3, 1865-1882.

30 H. Zhou, T. Fan and D. Zhang, ChemSusChem, 2011, 3, 513-528.

31 (a) K. Maeda, K. Teramura, D. Lu, T. Takata, N. Saito, Y. Inoue and K. Domen, Nature, 2006, 440, 295; (b) K. Maeda, M. Higashi, D. Lu, R. Abe and K. Domen, J. Am. Chem. Soc., 2010, 132, 5858-5868.

32 (a) H. Kotani, K. Ohkubo, Y. Takai and S. Fukuzumi, J. Phys. Chem. $B$, 2006, 110, 24047-24053; (b) H. Kotani, T. Ono, K. Ohkubo and S. Fukuzumi, Phys. Chem. Chem. Phys., 2007, 9, 1487-1492; (c) H. Kotani, R. Hanazaki, K. Ohkubo, Y. Yamada and S. Fukuzumi, Chem. - Eur. J., 2011, 17, 2777-2785.

33 HD was formed by the detection with GC as shown in Fig. S6a in the ESI. $\dagger$ HD is a coupling product in the reaction of $\mathrm{PyD}^{\bullet}$ and $\mathrm{PyH}^{\bullet}$ [eqn (4)].

34 Lower $\mathrm{H}_{2}$ formation efficiency in more non-polar $n$-heptane than cyclohexane may result from the lower numbers of weak secondary $\mathrm{C}-\mathrm{H}$ bonds in $n$-heptane. 